\title{
Vulnerabilidades em manchas urbanas ao longo das margens fluviais do Capibaribe - Pernambuco / Brasil
}

\section{Vulnerability in urban spots along the Capibaribe river margins - Pernambuco / Brazil}

\author{
João Paulo Gomes de Vasconcelos Aragão ${ }^{1}$ \\ Edvânia Torres Aguiar Gomes ${ }^{2}$
}

\begin{abstract}
Resumo
Concebendo margens de rios como ambientes complexos e importantes a inúmeras dinâmicas socioambientais, este artigo aponta semelhanças e especificidades de três manchas urbanas ao longo de um mesmo rio, detalhando processos de ocupação, usos e vulnerabilidades. O objetivo deste trabalho foi investigar a influência das formas de ocupação e uso do solo em distintas áreas urbanas nas margens do rio Capibaribe, localizado no estado de Pernambuco, visando a mitigação de vulnerabilidades. Para tanto, utilizou-se o método hipotético dedutivo, guiado pela linha de raciocínio sistêmica. A relação das manchas urbanas, no dinamismo da economia local e regional, com as margens do rio Capibaribe tem efetivado um quadro contraditório cujas marcas negativas apontam para a degradação ambiental e vulnerabilidade de populações de baixa renda nas margens fluviais do Capibaribe. Para mitigar estas consequências, devemse concretizar ações que atentem às variações locais de natureza das margens fluviais e dos dilemas sociais de ocupação e uso dos solos, bem como revisar as políticas existentes e o papel do Estado na gestão integrada das áreas de margens fluviais em manchas urbanas.
\end{abstract}

Palavras-chave: Rios; Cidade; Espaço; Rio Capibaribe.

\begin{abstract}
Conceiving riverbanks as complex and important environments for numerous socioenvironmental dynamics, this article points out similarities and specificities of three urban spots along the same river, detailing occupation processes, uses and vulnerabilities. The objective of this work was to investigate the influence of land occupation and land use patterns in distinct urban areas on the banks of the Capibaribe River, located in the state of Pernambuco, aiming to mitigate vulnerabilities. For that, the hypothetical deductive method, guided by the systemic reasoning line, was used. The relationship between urban spots in the local and regional economy and the banks of the Capibaribe River has made a contradictory picture of the negative signs that point to the environmental degradation and vulnerability of low income populations on the Capibaribe riverbanks.

\footnotetext{
${ }^{1}$ Instituto Federal de Pernambuco - IFPE (Campus Garanhuns), Garanhuns, Pernambucoo, Brasil. joao.aragao@garanhuns.ifpe.edu.br

2 Universidade Federal de Pernambuco - UFPE, Recife, Pernambuco, Brasil. torres@ufpe.br Artigo recebido em: 14/11/2016. Aceito para publicação em: 22/07/2019.
} 
In order to mitigate these consequences, actions must be carried out to address local variations in the nature of river banks and social dilemmas of land use and land use, as well as to review existing policies and the role of the State in the integrated management of riverbank areas in urban spots.

Keywords: Rivers; City; Space; Capibaribe river.

\section{Introdução}

As margens de rios são ambientes complexos e importantes a inúmeros processos socioambientais, desde aqueles relativos às formas de ocupação e uso do solo urbano, até as relações sistêmicas dos ambientes naturais componentes das bacias hidrográficas, nas quais as margens fluviais são elementos-chave.

A compreensão das margens de rios como faixa de terra de certa largura ao longo de um curso d'água, como explicam Guerra e Guerra (2006) e a ocupação ininterrupta dessas áreas orientaram a utilização das diretrizes do Código Florestal, Lei N 12.651 de 25 de maio de 2012, como um aporte relevante neste estudo.

Deste modo, concebem-se estas áreas como espaços essenciais à vida nos continentes, tendo em vista estarem relacionados ao ciclo biótico de várias espécies, além do ao ciclo hidrológico. Além do mais, ao longo da história, apresentam diferentes fins sociais, guardando marcas espaço temporais e técnicas, inclusive, das contradições sociais e ambientais das sociedades em sua (re)produção espacial (ARAGÃO, 2017).

Lastimavelmente, é perante os quadros de calamidade em cidades, derivados das inundações que impactam as populações ribeirinhas, que estas áreas ganham atenção das autoridades (GORSKI, 2010). Frisa-se que são diversas as formas de ocupação e de uso existentes, especialmente, quando observadas as dinâmicas contraditórias de produção do espaço urbano e seus agentes sociais (ARAGÃO; GOMES, 2016). 
Em face deste insistente quadro e de suas consequências socioambientais, o processo continuado de ocupação das margens de rios em cidades, exige iniciativas eficientes para a gestão, para as dinâmicas sociais que ocorrem nestas áreas e para a mitigação das vulnerabilidades existentes, sobretudo, àqueles grupos sociais de baixa renda.

Quanto a vulnerabilidade, entende-se que sua compreensão perpassa a leitura dos sistemas naturais (e.g. margens de rios), partindo da originalidade destes sistemas, sendo considerados, na evolução do tempo histórico, por meio das deliberações da sociedade sobre estas áreas e os reflexos destas ações, tanto sobre o meio natural, como sobre os arranjos socioambientais reconfigurados dialeticamente sobre o que se transforma em suporte ecológico, nos termos concebidos por Santos (2012).

Com isso, a vulnerabilidade em um dado espaço é concebida como uma construção social (MENDONÇA, 2004; THOURET, 2007; BRASIL, 2007; PORTO, 2007; SANTOS, 2015; PNUD, 2014) cuja origem está vinculada com a) a apropriação dos sistemas naturais pelos grupos sociais, b) a fragilidade do próprio sistema natural às formas de ocupação e uso do solo e c) às condições de ação efetivadas no contraditório e conflituoso contexto das classes sociais.

Partindo destes preceitos, foi objetivo central investigar a influência das formas de ocupação e uso do solo em áreas urbanas ao longo das margens do rio Capibaribe, situado no estado de Pernambuco, com vistas a mitigação de vulnerabilidades. Para tanto, adotou-se o método hipotético dedutivo (POPPER, 2013), guiada pelo raciocínio sistêmico (MONTEIRO, 2001).

Segundo Popper (2013), a análise sobre a realidade dá-se mediante a busca pela falseabilidade de hipóteses que sejam verificáveis e que, se confirmadas, tenha-se nelas uma verdade provisória que pode se considerar pertinente até descobrir sua falseabilidade, sendo a partir de então produzida outra hipótese. 
Ao observar a natureza das margens de rios em áreas urbanas, crê-se, à luz de Monteiro (2001) que o estabelecimento de hipóteses sejam viáveis, desde que consideradas as relações entre os elementos naturais e sociais de forma sistêmica. Desta feita, questionou-se como a ocupação e uso dos solos em margens de rios, em áreas urbanas, dispostas de montante à jusante de um curso d'água, influem nas vulnerabilidades existentes nestas áreas.

No limiar do estudo, concebeu-se hipoteticamente que a dificuldade de intervenções eficientes por parte do Estado, gerenciando de forma integrada as cidades distribuídas ao longo das margens de um mesmo rio, contribui para que as formas de ocupação e uso urbano dos solos reproduzam condições espaciais de vulnerabilidade socioambiental, principalmente, aos grupos sociais de menor poder aquisitivo segregados nos setores de maior instabilidade das margens fluviais.

Neste sentido, também inferiu-se a partir de, Tricart (1977, 1992), Ab'Saber (1994, 1969), Sotchava (1978), Ross (1995), Bertrand (1968), que cada sub-região de uma bacia hidrográfica, composta por diferentes subsistemas climático geomorfológicos, apresenta uma combinação diferenciada de interdependência entre arranjos naturais e sociais, refletidas na organização do espaço (SANTOS, 2006; 2012).

O estudo sopesou a bacia hidrográfica do rio Capibaribe (Figura 1) que está totalmente no estado de Pernambuco, em sua porção nordeste, unindo o semiárido, a zona da mata e o litoral. Esta bacia possui uma área de $7.454,88 \mathrm{~km}^{2}$, correspondendo a 7,58\% do território de Pernambuco e apresenta vazão média anual de $20,05 \mathrm{~m}^{3} / \mathrm{s}$ (SRHE/PE, 2010). Localiza-se entre $07^{\circ} 41^{\prime} 20^{\prime \prime}$ e $08^{\circ} 19^{\prime} 30^{\prime \prime}$ Sul e $34^{\circ} 51^{\prime} 00^{\prime \prime}$ e $36^{\circ} 41^{\prime} 58^{\prime \prime}$ WGr. Tem limites ao norte com a bacia do rio Goiana e Paraíba, no sul com a bacia do rio Ipojuca, para leste com o Oceano Atlântico e, a oeste, com a bacia do rio Ipojuca (APAC, 2012).

A partir sua nascente, situada entre os municípios de Poção e Jataúba, à sua foz no oceano Atlântico, através da cidade do Recife, o 
Capibaribe passa por 42 municípios, dos quais 15 estão integralmente inseridos na bacia e 27 dispõem de sua sede na bacia. A interação da bacia com distintas zonas climáticas confirma a complexidade da natureza existente na região drenada. A diversidade de formas de ocupação humanas estabelecidas torna este estrato geográfico ainda mais abrangente em termos de complexidade.

Figura 1. Municípios de Santa Cruz do Capibaribe, Limoeiro e São Lourenço da Mata Estado de Pernambuco e suas localizações na bacia hidrográfica do Capibaribe.

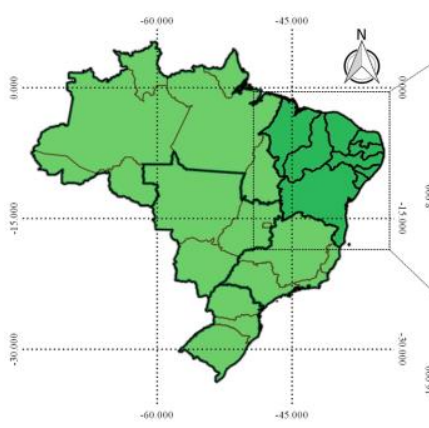

Legenda
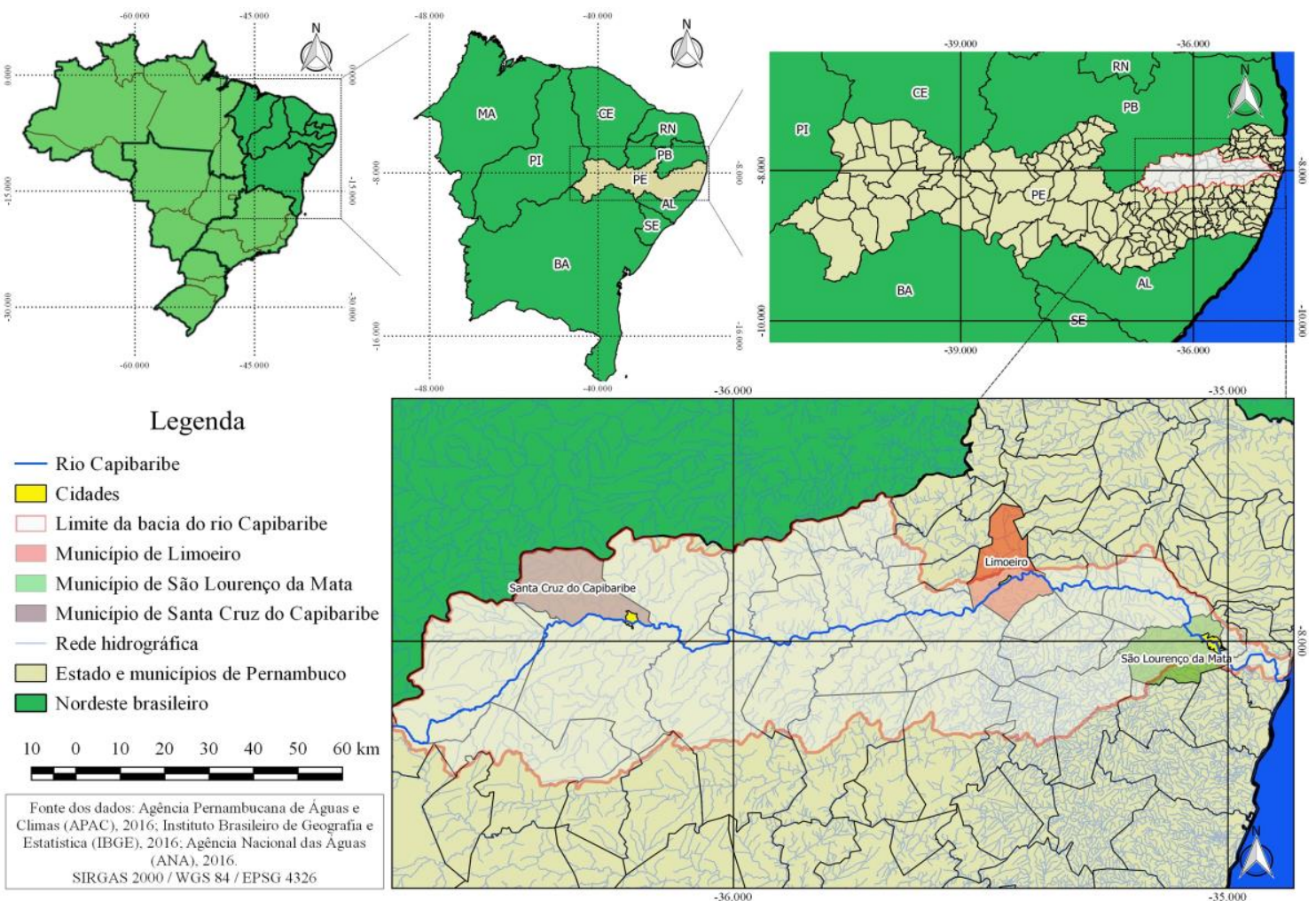

Fonte: Elaborado pelos autores, 2016.

Estas áreas podem ser caracterizadas atualmente pela elevada artificialização, tanto nos espaços rurais, onde predominam as atividades do setor primário, como nas manchas urbanas, onde se destacam as atividades da indústria, prestação de serviços e comércio, além dos grandes contingentes demográficos. As manchas urbanas, com diferentes densidades 
e extensões, estão dispostas parcialmente ao longo do percurso do rio principal e na área de drenagem desta bacia. Esta distribuição ocorre de um modo geral, desde o oeste até o leste da bacia, onde na fachada atlântica o Rio Capibaribe deságua.

Sete cidades estão dispostas ao longo do rio principal, em sequência, da nascente à foz: Sta. Cruz do Capibaribe, Toritama, Salgadinho, Limoeiro, Paudalho, São Lourenço da Mata e Recife (SRHE/PE, 2010). A elas somamse ao longo do percurso de portes inferiores, como distritos municipais, vilas e extensões urbanas para além do perímetro urbano.

O presente estudo considerou a cidade de Santa Cruz do Capibaribe e o distrito de São Domingo (no alto Capibaribe), a cidade de Limoeiro (médio Capibaribe) e a cidade São Lourenço da Mata mais as extensões urbanas externas ao perímetro urbano (baixo Capibaribe). As três cidades e as extensões urbanas associadas constituem manchas de ocupação humana ao longo das margens do rio Capibaribe e encontram-se em distintos territórios municipais situados parcial ou integralmente na região da bacia hidrográfica do rio Capibaribe (ARAGÃO; GOMES 2017).

Os municípios de Santa Cruz do Capibaribe e São Lourenço da Mata têm seus territórios quase que totalmente contidos na bacia do Capibaribe com, 99,74\% e 79,55\%, respectivamente. Já Limoeiro tem a porção centro sul de seu território banhada pelos afluentes e pelo rio Capibaribe, o equivalente a 51,42\% (SRHE/PE, 2010). Todos os três municípios com sede na investigação têm a cidade às margens do rio principal da bacia.

Conforme o Instituto Brasileiro de Geografia e Estatística (IBGE, 2016), em Santa Cruz do Capibaribe a população corresponde a 99.232 sendo 97,73\% urbana, Limoeiro 56.536, sendo 80\% urbana e São Lourenço da Mata 110.264 habitantes, sendo 94,05\% urbana. Indubitavelmente, todas as cidades espelham em sua paisagem urbana os problemas e carências encontrados por suas populações, tal como em todas aglomerações urbanas 
da bacia, seja em termos de infraestrutura, seja em perspectivas econômicosociais (ARAGÃO; GOMES, 2016).

Como instrumentos metodológicos foram utilizados: a) revisão da literatura sobre vulnerabilidade, margens de rios, rios, produção do espaço urbano e relação Sociedade - Natureza; b) levantamento de informações secundárias junto aos órgãos da administração pública, mais as observações de campo; c) construção cartográfica, análise de imagens de satélite (obtidas através do aplicativo Google Earth); e d) produção de iconografias e tabelas analíticas.

\section{Vulnerabilidades em manchas urbanas ao longo das margens fluviais do rio Capibaribe}

Para a Organização das Nações Unidas (PNUD, 2014) o conceito de vulnerabilidade relaciona-se com a susceptibilidade de algo não desejado acontecer, como um furacão, terremoto ou enchente, uma grande crise econômica que gere desemprego em massa, crises sanitárias, conflitos civis, uma grave epidemia patológica, entre outros.

Segundo o PNUD (2014) a vulnerabilidade esta diretamente relacionada com as condições sócio econômicas da população, sendo mais visível com aqueles que vivem na extrema pobreza. Em certos momentos, dadas as circunstâncias demográficas, políticas e/ou ambientais, a vulnerabilidade pode ser intensificada. Apesar da intervenção da ONU, o debate teórico acerca deste tema encontra-se em fase embrionária, sendo por isso pequeno e, até recentemente, ocupado por concepções tecnocratas como apontam Hewitt (1983) e Aledo e Sulaiman (2014).

As discussões sobre vulnerabilidade emanam da insuficiência empírica e teórica das concepções tecnocratas sobre desastres naturais, as quais desprezavam a questão da vulnerabilidade para o entendimento dos riscos ambientais e de seus fatores sociais. Para esta linha de pensamento, 
os desastres naturais não dispõem de relações diretas com questões sociais e são explicados por fatores físicos extremos, sendo objeto às altenativas de gestão através do uso de tecnologias (QUARANTELLI, 1998).

Com base em Aledo e Sulaiman (2014) a visão de vulnerabilidade que se propõe considera os desastres como fenômenos socioambientais (sociedade + natureza), sendo compostos também por fatores sócio históricos, portanto. Além disso, os efeitos se distribuem de forma desigual conforme os aspectos socioeconômicos da população no tempo e no espaço (ARAGÃO, 2017).

Acredita-se também que o encadeamento de cada momento histórico dispõe de um elemento espacial expresso explicitamente nas ações políticas, na forma de organização social no território e nas atividades econômicas que constituem cada lugar (ARAGÃO, 2017). Em acordo com esta linha de raciocínio crê-se numa perspectiva de vulnerabilidade contextualizada à sociedade e sua composição cultural, política e econômica (WISNER et al., 2004).

Neste estudo, a delimitação física das margens fluviais não deve ser absoluta já que, enquanto porção do "espaço", não é apenas uma área de certa metragem, mas ambiente apropriado nas dinâmicas de reprodução espacial, o que permite o entendimento de como se dá a vulnerabilidade socioambiental a partir da relação sociedade-natureza e como se apresenta na trama cotidiana do espaço social. Esta manifestação será mais contundente em contextos socioeconômicos desfavoráveis, sobremaneira em ambientes de considerável fragilidade socioambiental, como as margens de rios.

Desta feita, ao observar reportagens, documentos oficiais, fotografias, registros jornalísticos históricos disponíveis nas bibliotecas municipais, acervos pessoais de munícipes, sites oficiais, blogues da internet, além do testemunho de pessoas residentes em áreas de margens fluviais, tem-se retratadas cenas de desespero, prejuízo e danos causados em períodos de enchentes do rio Capibaribe, amplificadas em forma de inundação. 
Neste ínterim, nos séculos XIX e XX em Pernambuco, foram registradas inundações, inclusive, no rio Capibaribe, concebidas como catastróficas em 1842, 1854, 1869, 1897, 1924, 1965, 1966, 1970 e 1975, segundo a Secretaria de Recursos Hídricos e Energéticos de Pernambuco (2010). Datam de meados do século XX os debates realizados pela Superintendência de Desenvolvimento Regional do Nordeste (SUDENE), nos quais técnicos e estudiosos apontam para a necessidade de construção de barragens, medida estrutural, dirigida para o controle de inundações a partir de rios em cidades (ARAGÃO, 2017).

Apesar das obras infraestruturais de contenção de enchentes efetivadas pelo Estado, desde 1975, verifica-se nas cidades investigadas que episódios de inundação, associados à períodos de escassez hídrica, além de problemas associados à poluição hídrica, têm continuado até os dias atuais devido ao processo ininterrupto de construção de edificações nas margens do rio Capibaribe (ARAGÃO; GOMES, 2016), especialmente por classes sociais com elevada vulnerabilidade (Figura 2).

Apesar de conter o volume extraordinário das águas em períodos de elevada pluviosidade com obras estruturais, especialmente barragens, o Estado não tem estabelecido limites para a ocupação das margens. A dinâmica do setor imobiliário e a demanda crescente por habitação nas cidades, têm aumentado sobre as margens do rio Capibaribe os processos formais e informais de ocupação. Tem-se com isso o estreitando gradativo do leito que, haja vista a retirada da mata ciliar, perde profundidade e largura, intensificando a ocorrência de inundações mesmo com as barragens construídas à montante. 
Figura 2. Localização, em relação às margens do rio Capibaribe, de formas de ocupação inadequadas de uso residencial nas cidades de Santa Cruz do Capibaribe (a), Limoeiro (b e c) e São Lourenço da Mata (d).

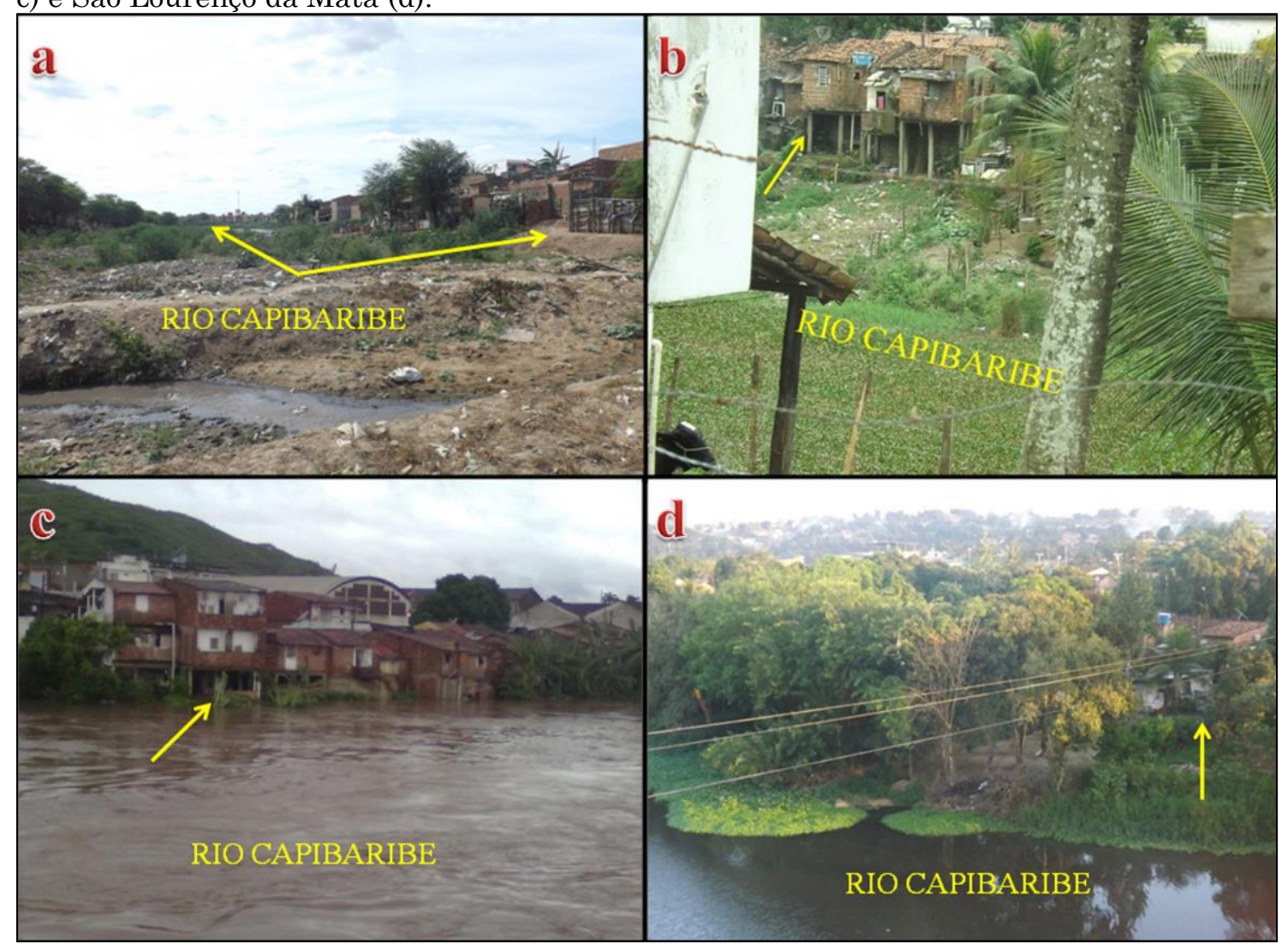

Fotos: Aragão, 2011 (c) e 2015 (a - b - d).

O resultado tão quão catastrófico às grandes enchentes da segunda metade do século XX, são os atuais níveis de poluição das águas do rio que amplificam prejuízos à saúde pública, em especial, dos grupos sociais mais vulneráveis quando das inundações e constantes crises de abastecimento urbano. Com isto, o quadro tende a tornar-se mais delicado à medida que o rio passa por cada mancha urbana, intensificando os prejuízos.

O tratamento a estas questões em Pernambuco e no Brasil ainda é deficiente na esfera local por apresentar lacunas nas legislações pertinentes à produção de áreas urbanas, à proteção ambiental e à justiça social. Apesar disto, registra-se o avanço na esfera legal (SRHE/PE, 2010) com a criação de instrumentos legais, como o Plano Estadual de Recursos Hídricos do Estado de Pernambuco, instituído em 1998, o Plano Diretor de Recursos Hídricos da 
Bacia Hidrográfica do Rio Capibaribe, criado em 2001, o Plano Nacional de Recursos Hídricos, constituído em 2006, e o Plano Hidroambiental da Bacia Hidrográfica do Rio Capibaribe, criado em 2010. Na contramão destes avanços, destaca-se ainda a insuficiência de estatísticas a respeito da realidade socioambiental em cada município como se observa no quadro a seguir (Quadro 01).

Quadro 1 Aspectos da gestão das cidades e instrumentos ausentes e existentes

\begin{tabular}{|c|c|c|c|c|c|c|}
\hline Municípios & \multicolumn{2}{c}{$\begin{array}{c}\text { Sta. Cruz do } \\
\text { Capibaribe }\end{array}$} & \multicolumn{2}{c|}{ Limoeiro } & \multicolumn{2}{c|}{$\begin{array}{c}\text { São Lourenço da } \\
\text { Mata }\end{array}$} \\
\hline Instrumentos & Ausência & Existe & Ausência & Existe & Ausência & Existe \\
\hline Plano Diretor Municipal & & $\mathrm{X}$ & & $\mathrm{X}$ & & $\mathrm{X}$ \\
\hline Lei Orgânica Municipal & & $\mathrm{X}$ & & $\mathrm{X}$ & & $\mathrm{X}$ \\
\hline $\begin{array}{c}\text { Conselho Mun. De Meio } \\
\text { Ambiente }\end{array}$ & & $\mathrm{X}$ & $\mathrm{X}$ & & $\mathrm{X}$ & \\
\hline $\begin{array}{c}\text { Licenciamento } \\
\text { ambiental no município }\end{array}$ & $\mathrm{X}$ & & $\mathrm{X}$ & & $\mathrm{X}$ & \\
\hline Participa do COBH & & $\mathrm{X}$ & & $\mathrm{X}$ & & $\mathrm{X}$ \\
\hline $\begin{array}{c}\text { Verbas para serviços } \\
\text { ambientais - gov. } \\
\text { Federal }\end{array}$ & & $\mathrm{X}$ & $\mathrm{X}$ & & & $\mathrm{X}$ \\
\hline Plano de contingência & & $\mathrm{X}$ & $\mathrm{X}$ & & & $\mathrm{X}$ \\
\hline $\begin{array}{c}\text { Conselho de Política } \\
\text { Urbana }\end{array}$ & $\mathrm{X}$ & & $\mathrm{X}$ & & $\mathrm{X}$ & \\
\hline $\begin{array}{c}\text { Leis específica de área } \\
\text { de relevância social }\end{array}$ & $\mathrm{X}$ & & $\mathrm{X}$ & & & $\mathrm{X}$ \\
\hline $\begin{array}{c}\text { Lei de zona de proteção } \\
\text { ambiental }\end{array}$ & $\mathrm{X}$ & & $\mathrm{X}$ & & & $\begin{array}{c}\mathrm{X} \\
\left(2006^{*}\right.\end{array}$ \\
\hline $\begin{array}{c}\text { Lei de impacto de } \\
\text { vizinhança e preempção }\end{array}$ & $\mathrm{X}$ & & & $\mathrm{X}$ & $\mathrm{X}$ & \\
\hline $\begin{array}{c}\text { Lei de zoneamento e uso } \\
\text { e ocupação do solo }\end{array}$ & $\mathrm{X}$ & & & $\begin{array}{c}\mathrm{X} \\
\left(1984^{*}\right)\end{array}$ & & $\begin{array}{c}\mathrm{X} \\
\left(2006^{*}\right)\end{array}$ \\
\hline $\begin{array}{c}\text { Fundo municipal de } \\
\text { meio ambiente }\end{array}$ & $\mathrm{X}$ & & $\mathrm{X}$ & & $\mathrm{X}$ & \\
\hline $\begin{array}{c}\text { Relações com órgãos } \\
\text { estaduais e federais }\end{array}$ & & $\mathrm{X}$ & $\mathrm{X}$ & & & $\mathrm{X}$ \\
\hline
\end{tabular}

*Ano de criação.

Fonte: Elaborado pelo autor a partir de dados da MUNIC/IBGE (2012), 2016.

O quadro acima permite identificar instrumentos cujas lacunas podem impactar negativamente na gestão das margens de rios, uma vez que estes espaços são incorporados de forma efetiva na dinâmica econômica, política e socioambiental das cidades. A expansão dos sistemas técnicos 
fomentadores das formas de ocupação e usos não é, contudo, acompanhada da preocupação com as características ambientais das margens de rios, o que provoca, para os grupos de baixa renda, que ocupam de forma desordenada estas áreas, uma situação de vulnerabilidade que reflete as contradições e as desigualdades de acesso às estruturas básicas do espaço urbano.

A expansão dos sistemas técnicos ocorre de forma sistemática, solidária e contraditória (Santos, 2006), atendendo às funcionalidades e necessidades que cada região, município, cidade e/ou setor estratégico requer, do ponto de vista econômico, em cada tempo histórico. Toma-se como exemplo o aumento do número de ligações de energia, concomitante à ampliação da demanda por água, seja para o abastecimento de casas, seja de unidades industriais e comerciais.

No ano de 1985 a quantidade de consumidores de energia elétrica nos municípios com sede nas manchas urbanas investigadas era de 25.940. Em 2015 , este quantitativo ultrapassava os 100.000 , um aumento de quase 300\% (CELPE, 2016). Entre 1984 e 2015, constatou-se igualmente um aumento no número de ligações e economias abastecidas pela rede de água. De 26.300 ligações em 1984, passa-se a um número de 55.247 em 2015, equivalendo a mais de 100\% de crescimento (COMPESA, 2009).

O traço histórico comum da produção dos espaços das manchas urbanas deste estudo remonta a integração das mesmas pela rede de rodovias federais BR's 101, 232 e 104 e rodovias estaduais PE's 090 e 050. Estas vias de acesso permitiram a expansão dos serviços prestados em cada sede de município, fato este que viabiliza a intensificação do processo de ocupação no interior destas cidades nos últimos 50 anos (VILAÇA, 1973; MORA e SARABIA, 2009).

Um reflexo desta integração, apontada por Aragão (2017), é um aumento da frota de veículos, especialmente caminhões, que trafegam com mercadorias, e ônibus que atuam entre municípios da região, evidenciando 
sua funcionalidade econômico produtiva. Dados do Departamento Estadual de Trânsito de Pernambuco (DETRAN, 2015) indicam que houve um aumento superior a $100 \%$ na frota de caminhões e de quase $50 \%$ da frota de ônibus, entre 1.999 e 2015 em Santa Cruz o Capibaribe, Limoeiro e São Lourenço da Mata, o que ratifica um processo contundente de circulação de mercadorias e trabalhadores. Nos três, haviam no ano de 1999, 833 caminhões e 431 ônibus. Estes números passam a ser de 1.995 caminhões e 609 ônibus no ano de 2015.

Recentemente, a expansão de serviços bancários que atendem ao número crescente de indústrias, comércios, serviços e pessoas nos municípios destacados, sobretudo, em suas sedes urbanas, indica o direcionamento dos sistemas técnicos para atendimento da dinâmica econômica, além da intensa financeirização da atividades. Entre 2010 e 2014, o total de bancos existentes nas três cidades aumenta de 13 para 17 (BANCO CENTRAL DO BRASIL, 2014).

Este aumento encontra relação com a ampliação de atividades tradicionalmente urbanas, como indústria de transformação, que aumenta de 507 unidades no ano de 1998, para 1430, em 2014; construção civil, de 49, ano de 1998, para 148 em 2014; comércios, de 1.462, no ano de 1998, para 3.318, em 2014; e serviços de 510, ano de 1998, para 1.438, em 2014; considerando os municípios de Santa Cruz do Capibaribe, Limoeiro e São Lourenço da Mata juntos (MINISTÉRIO DO TRABALHO E EMPREGO, 2016).

A expansão destes sistemas ilustra o crescimento geral das manchas urbanas, sobremaneira as cidades investigadas e a ligação destas com a dinâmica econômica que se consolida numa rede urbana estruturada pelo Estado. No interior de cada cidade, verifica-se uma dinâmica imobiliária intensa e que não dispõe de limites para a ocupação das margens do rio Capibaribe. 
$\mathrm{Na}$ análise não foi detectada nenhum tipo de ação específica que regulamentasse a ocupação das margens do rio Capibaribe, tampouco uma preocupação específica com as áreas de maior vulnerabilidade social, o que comprova a ausência de ações voltadas para o planejamento de uso e ocupação dos solos, bem como de conservação para estas áreas (ARAGÃO; GOMES, 2017).

Devido a esta realidade o processo de ocupação das margens do rio Capibaribe ocorre de forma ininterrupta e desregulamentada até os dias atuais. Como consequência, verifica-se o crescimento de impactos negativos sobre o rio e de riscos que tendem a se materializar, principalmente, sobre os grupos sociais mais vulneráveis (Quadro 2).

Na cidade de Santa Cruz do Capibaribe, a década de 1980, principia grandes transformações econômicas, uma vez que "o fenômeno de expansão da atividade urbana de confecção na cidade [...] ocorreu em decorrência da necessidade de geração de emprego e renda para a população da cidade após a queda da lavoura do algodão na região" (MORA; SARABIA; XAVIER, 2006, p. 7).

A ocupação desordenada do rio Capibaribe e suas margens promove o crescimento da vila de São Domingos que, apesar de pertencer ao município de Brejo da Madre de Deus, cresce aliado à dinâmica da produção têxtil de Santa Cruz do Capibaribe. Vista do alto, é possível considerar se tratar da mesma cidade, embora, ao atravessar a ponte que cruza o Capibaribe, esteja passando de um município a outro, de uma cidade para um distrito. 
Quadro 2. Formas de uso dos solos nas áreas de margens do rio Capibaribe nas manchas urbanas de Santa Cruz do Capibaribe, Limoeiro e São Lourenço e impactos correlatos atualmente.

\begin{tabular}{|c|c|c|c|c|c|c|c|}
\hline \multicolumn{2}{|c|}{ Cidades } & \multirow{2}{*}{\multicolumn{2}{|c|}{$\begin{array}{l}\text { Santa Cruz do } \\
\text { Capibaribe }\end{array}$}} & \multirow{2}{*}{\multicolumn{2}{|c|}{ Limoeiro }} & \multirow{2}{*}{\multicolumn{2}{|c|}{$\begin{array}{c}\text { São } \\
\text { Lourenço } \\
\text { da Mata }\end{array}$}} \\
\hline Usos do solo & Impactos & & & & & & \\
\hline \multirow{4}{*}{ Residencial } & $\begin{array}{c}\text { Supressão de cobertura } \\
\text { vegetal }\end{array}$ & \multirow{4}{*}{$\mathbf{X}$} & $\mathrm{X}$ & \multirow{4}{*}{$\mathbf{X}$} & $\mathrm{X}$ & \multirow{4}{*}{$\mathbf{X}$} & $\mathrm{X}$ \\
\hline & Impermeabilização do solo & & $\mathrm{X}$ & & $\mathrm{X}$ & & $\mathrm{X}$ \\
\hline & $\begin{array}{c}\text { Lançamento de efluentes } \\
\text { domésticos no rio }\end{array}$ & & $\mathrm{X}$ & & $\mathrm{X}$ & & $\mathrm{X}$ \\
\hline & $\begin{array}{l}\text { Despejo indevido de } \\
\text { resíduos sólidos }\end{array}$ & & $\mathrm{X}$ & & $\mathrm{X}$ & & $\mathrm{X}$ \\
\hline \multirow{3}{*}{ Indústria } & $\begin{array}{l}\text { Supressão de cobertura } \\
\text { vegetal }\end{array}$ & \multirow{3}{*}{$\mathbf{X}$} & $\mathrm{X}$ & \multirow{3}{*}{$\mathbf{X}$} & $\mathrm{X}$ & \multirow{3}{*}{$\mathbf{X}$} & $\mathrm{X}$ \\
\hline & Impermeabilização do solo & & $\mathrm{X}$ & & $\mathrm{X}$ & & $\mathrm{X}$ \\
\hline & $\begin{array}{l}\text { Lançamento de efluentes } \\
\text { industriais no rio }\end{array}$ & & $\mathrm{X}$ & & $\mathrm{X}$ & & $\mathrm{X}$ \\
\hline \multirow{4}{*}{ Comércio formal } & $\begin{array}{l}\text { Supressão da cobertura } \\
\text { vegetal }\end{array}$ & \multirow{4}{*}{$\mathbf{X}$} & $\mathrm{X}$ & \multirow{4}{*}{$\mathbf{X}$} & $\mathrm{X}$ & \multirow{4}{*}{$\mathbf{X}$} & $\mathrm{X}$ \\
\hline & Impermeabilização do solo & & $\mathrm{X}$ & & $\mathrm{X}$ & & $\mathrm{X}$ \\
\hline & Lançamento de efluentes & & $\mathrm{X}$ & & $\mathrm{X}$ & & $\mathrm{X}$ \\
\hline & $\begin{array}{c}\text { Produção de resíduos } \\
\text { sólidos para escoamento } \\
\text { difuso }\end{array}$ & & $\mathrm{X}$ & & $\mathrm{X}$ & & $\mathrm{X}$ \\
\hline \multirow{3}{*}{ Comércio informal } & $\begin{array}{c}\text { Supressão da cobertura } \\
\text { vegetal }\end{array}$ & \multirow{3}{*}{$\mathbf{X}$} & & \multirow{3}{*}{$\mathbf{X}$} & & \multirow{3}{*}{$\mathbf{X}$} & \\
\hline & Impermeabilização do solo & & $\mathrm{X}$ & & $\mathrm{X}$ & & $\mathrm{X}$ \\
\hline & $\begin{array}{c}\text { Produção de resíduos } \\
\text { sólidos para escoamento } \\
\text { difuso } \\
\end{array}$ & & $\mathrm{X}$ & & $\mathrm{X}$ & & $\mathrm{X}$ \\
\hline \multirow{4}{*}{$\begin{array}{l}\text { Serviços (educação, saúde, } \\
\text { escritórios de seguros, } \\
\text { oficinas, contabilidade, etc.) }\end{array}$} & $\begin{array}{c}\text { Supressão da cobertura } \\
\text { vegetal }\end{array}$ & \multirow{4}{*}{$\mathbf{X}$} & $\mathrm{X}$ & \multirow{4}{*}{$\mathbf{X}$} & $\mathrm{X}$ & \multirow{4}{*}{$\mathrm{X}$} & $\mathrm{X}$ \\
\hline & Impermeabilização do solo & & $\mathrm{X}$ & & $\mathrm{X}$ & & $\mathrm{X}$ \\
\hline & Lançamento de efluentes & & $\mathrm{X}$ & & $\mathrm{X}$ & & $\mathrm{X}$ \\
\hline & $\begin{array}{c}\text { Produção de resíduos } \\
\text { sólidos para escoamento } \\
\text { difuso }\end{array}$ & & $\mathrm{X}$ & & $\mathrm{X}$ & & $\mathrm{X}$ \\
\hline \multirow{3}{*}{ Lazer e esportes } & $\begin{array}{c}\text { Supressão da cobertura } \\
\text { vegetal }\end{array}$ & & & \multirow{3}{*}{$\mathbf{X}$} & $\mathrm{X}$ & \multirow{3}{*}{$\mathbf{X}$} & $\mathrm{X}$ \\
\hline & Impermeabilização do solo & & & & $\mathrm{X}$ & & $\mathrm{X}$ \\
\hline & Lançamento de efluentes & & & & $\mathrm{X}$ & & $\mathrm{X}$ \\
\hline \multirow[b]{2}{*}{ Pecuária } & $\begin{array}{c}\text { Supressão da cobertura } \\
\text { vegetal }\end{array}$ & \multirow[b]{2}{*}{$\mathbf{X}$} & $\mathrm{X}$ & \multirow[b]{2}{*}{$\mathbf{X}$} & $\mathrm{X}$ & & \\
\hline & $\begin{array}{c}\text { Exposição do solo a } \\
\text { processos erosivos } \\
\text { acelerados }\end{array}$ & & $\mathrm{X}$ & & $\mathrm{X}$ & & \\
\hline \multirow{3}{*}{ Extrativismo } & $\begin{array}{c}\text { Supressão da cobertura } \\
\text { vegetal } \\
\end{array}$ & & $\mathrm{X}$ & & & & \\
\hline & $\begin{array}{c}\text { Exposição do solo a } \\
\text { processos erosivos } \\
\text { acelerados } \\
\end{array}$ & $\mathbf{X}$ & $\mathrm{X}$ & & & & \\
\hline & Poluição do rio e de & & $\mathrm{X}$ & & & & \\
\hline
\end{tabular}




\begin{tabular}{|c|c|c|c|c|c|c|c|}
\hline & lençóis subterrâneos & & & & & & \\
\hline \multirow{3}{*}{ Agrícola } & $\begin{array}{c}\text { Supressão da cobertura } \\
\text { vegetal }\end{array}$ & \multirow{3}{*}{$\mathrm{X}$} & $\mathrm{X}$ & \multirow{3}{*}{$\mathrm{X}$} & $\mathrm{X}$ & \multirow{3}{*}{$\mathrm{X}$} & $\mathrm{X}$ \\
\hline & $\begin{array}{c}\text { Exposição do solo a } \\
\text { processos erosivos } \\
\text { acelerados }\end{array}$ & & $\mathrm{X}$ & & $\mathrm{X}$ & & $\mathrm{X}$ \\
\hline & Lançamento de efluentes & & $\mathrm{X}$ & & $\mathrm{X}$ & & $\mathrm{X}$ \\
\hline
\end{tabular}

Fonte: Elaborado pelos autores, 2016.

O crescimento acelerado impulsionado pelo capital da indústria têxtil, consorciado ao Estado, fornecedor das estruturas de operação, condiciona a ocupação das áreas de margens do rio Capibaribe, com a produção de lotes que vêm sendo ocupados por residências, lojas de calçados, igrejas, mercadinhos e outros pequenos estabelecimentos, nos quais assenta-se a classe trabalhadora.

A ausência de infra estrutura de saneamento e a disposição indevida de lixo sobre o rio Capibaribe e suas margens dão ao ambiente fluvial um aspecto de abandono o que reflete, não apenas a precária assistência do Estado, mas também a falta de priorização da conservação ambiental dos grupos sociais residentes na área, bem como das empresas que têm galgado processos de impulso ao crescimento econômico da região.

Este quadro ganha ainda um agravante devido às condições climáticas regionais. Localizada no semiárido, a cidade de Santa Cruz do Capibaribe e o distrito de São Domingos, sofrem com o abastecimento hídrico, sendo semi periodicamente atingidas por inundações. Além disso, a possibilidade de extração de água em leito seco é, em extensas faixas, inviabilizada devido à forte contaminação do rio Capibaribe.

A economia neoliberal globalizada, pautada na seletividade espacial das empresas, propicia aos grandes empreendimentos comerciais e de serviços, organizados em redes de distintas escalas, mas visivelmente rotativos nos lugares, a capacidade de indução de mão de obra, bem como recursos financeiros e infraestruturas de transporte, comunicação, abastecimento, além de incentivos fiscais, mediadas pelo Estado. 
Tal processo encontra capilaridade no Brasil, mas efetiva-se de forma destacada somente em alguns centros urbanos, provocando rápida saturação dos postos de emprego e como consequência, haja vista a ampliação dos fluxos demográficos a estes centros urbanos, a, ampliação do setor informal, além do crescimento do mercado imobiliário. Tal processo é bem exemplificado, a partir de 1970, em cidades como Limoeiro (VILAÇA, 1973).

Dadas as condições de escassez da terra no centro da cidade e a deficiente infraestrutura urbana que liga os loteamentos mais distantes ao centro comercial de Limoeiro, a construção de pequenos loteamentos nas margens do rio Capibaribe, tem ocorrido na atualidade, além de intervenções como aterro de rios tributários, disposição indevida de lixo, despejo de efluentes domésticos e urbanos in natura no rio, entre outras,.

Concomitante a estas contradições, os quadros de vulnerabilidade na cidade de Limoeiro não são resolvidos o que reforça a possibilidade de concretização de riscos a cada nova enchente amplificada em inundação, como ocorrido em 2011, quando o aumento do volume das águas do rio Capibaribe na cidade atingiu comunidades, como a da Barriguda, situada no centro urbano, à margem esquerda do rio Capibaribe.

No baixo Capibaribe, aglutinando em suas margens o maior contingente populacional entre as três sedes municipais investigadas, a malha urbana de São Lourenço da Mata tem-se constituído hoje como cidade dormitório, concedendo força de trabalho à capital estadual, Recife, além das novas áreas de dinamismo econômico situadas nos litorais, norte e sul de Pernambuco (ARAGÃO; GOMES, 2016), Goiana (polo farmacoquímico, vidreiro e automobilístico) e Ipojuca (porto indústria de Suape).

A (re)produção deste espaço urbano integra-se às repercussões da organização dos sistemas técnicos, os quais se concentram na capital ou em áreas previamente selecionadas pelo capital. A crescente mão de obra situada na Região Metropolitana do Recife e os nítidos impactos 
socioambientais registrados na paisagem do rio Capibaribe compõem este processo.

Neste âmbito, a lei Orgânica Municipal de São Lourenço da Mata referencia-se, como tantas outras, na constituição brasileira para afirmar em sua Secção XI, Art. 102 B, "o direito ao meio ambiente ecologicamente equilibrado, bem de uso comum do povo e essencial à sadia qualidade de vida, cabendo ao Município e à coletividade o dever de defendê-lo e preserválo para as gerações presentes e futuras" (PREFEITURA MUNICIPAL DE SÃO LOURENÇO DA MATA, 2008).

Apesar da menção ao principal artigo sobre meio ambiente na constituição federativa do Brasil, são explícitas as evidências de que o poder público (não apenas em São Lourenço da Mata) não tem encontrado meios de garantir este direito aos cidadãos e cidadãs, haja vista os preceitos, considerados prioritários pelo capital e pelo próprio Estado, para integrar-se ao movimento de modernização das estruturas produtivas.

Impulsionadas pelas forças econômicas, a ocupação das margens fluviais do Capibaribe ocorre intensamente nas últimas cinco décadas, desprovida da atenção do Estado quanto aos danos causados nas cidades, mesmo perante a crescente de criação de leis ambientais na esfera estadual e federal e, de forma menos sistemática, na esfera municipal.

Em todas as realidades observadas riscos como, inundações em áreas densamente ocupadas, doenças ligadas à água contaminada, proliferação de vetores, desvalorização das áreas de margens fluviais, Prejuízos socioeconômicos às atividades formais e informais, desabamentos de edificações, déficit de abastecimento associado à inundação de áreas densamente povoadas, deterioração do patrimônio cultural material (prédios históricos), diminuição dos trechos com mata ciliar e desequilíbrios na biodiversidade, são comuns.

Todavia, acredita-se que a organização peculiar sub regional entre fatores naturais, ambientais e sociais, torna necessária a revisão das 
políticas e instrumentos de gestão urbana, ambiental e dos recursos hídricos existentes, em cada cidade, haja vista as particularidades de cada realidade local, como presumem Aragão e Gomes (2016; 2017) e Aragão (2017). A análise destes autores sobre as manchas urbanas centralizadas pelas cidades de Santa Cruz do Capibaribe, Limoeiro e São Lourenço da Mata, permitiu sintetizar três grupos de fatores de vulnerabilidade socioambiental, quais sejam, sociais, naturais e ambientais (Figura 3).

Figura 3. Fatores e níveis de vulnerabilidade socioambiental em áreas de margens de rios em cidades.

\begin{tabular}{|c|c|c|}
\hline Fatores & $\begin{array}{l}\text { Níveis de comprometimento por fatores em áreas de } \\
\text { margens de rios em cidades }\end{array}$ & $\begin{array}{l}\text { Vulnerabilidade } \\
\text { socioambiental }\end{array}$ \\
\hline \multirow{3}{*}{ 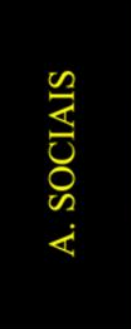 } & $\begin{array}{l}\text { 3. Estrutura socioeconômica de baixa renda, precária condição de } \\
\text { saneamento básico e ausência ou baixo poder de representação } \\
\text { comunitária; }\end{array}$ & $\begin{array}{c}9 \text { ALTA } \\
\text { A. } 3 ; \mathrm{B} 3 ; \mathrm{C} 3\end{array}$ \\
\hline & $\begin{array}{l}\text { 2. Estrutura socioeconômica de baixa a média renda, precária condição de } \\
\text { saneamento básico e baixo poder de representação comunitária; }\end{array}$ & $\begin{array}{c}\text { 8 ALTA } \\
\text { "X".3; "Y". 3; "Z".2 }\end{array}$ \\
\hline & $\begin{array}{l}\text { 1. Estrutura socioeconômica de média e alta renda e baixo poder de } \\
\text { representação comunitária. }\end{array}$ & $\begin{array}{c}7 \text { ALTA } \\
\text { "X".3; "Y".2; " } \mathrm{Z} " .2\end{array}$ \\
\hline \multirow{3}{*}{ 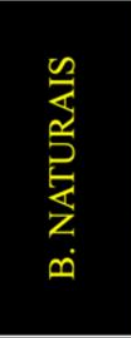 } & $\begin{array}{l}\text { 3. Área de déficit hídrico e passivel a chuvas intensas e cheias fluviais com } \\
\text { inundação de área urbana; }\end{array}$ & $\begin{array}{c}6 \text { MÉDIA } \\
\text { "X".3; "Y".2; "Z".1 }\end{array}$ \\
\hline & $\begin{array}{l}\text { 2.Área sem déficit hídrico e passivel a chuvas intensas e cheias fluviais } \\
\text { com inundação de área urbana; }\end{array}$ & $\begin{array}{c}5 \text { MÉDIA } \\
\text { "X".3; "Y". } 1 ; " \text { "Z".1 }\end{array}$ \\
\hline & $\begin{array}{l}\text { 1. Área sem déficit hídrico e sem possibilidades momentânea de cheias e } \\
\text { inundações. }\end{array}$ & $\begin{array}{l}4 \text { MÉDIA } \\
\text { A.2; B.2; C. } 2\end{array}$ \\
\hline \multirow{3}{*}{ 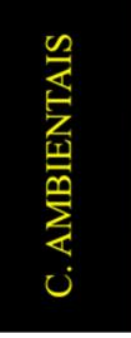 } & $\begin{array}{l}\text { 3. População residente ou a trabalho em área de instabilidade } \\
\text { hidrogeomorfológica, passivel a desapropriação, deslizamentos, danos } \\
\text { estruturais e doenças por contato com água contaminada e/ou vetores; }\end{array}$ & $\begin{array}{c}\text { 3 BAIXA } \\
\text { "X".2; "Y".2; “Z".1 }\end{array}$ \\
\hline & $\begin{array}{l}\text { 2. População residente ou a trabalho em área de instabilidade } \\
\text { hidrogeomorfológica, passivel a danos estruturais e doenças por contato } \\
\text { com água contaminada e/ou vetores; }\end{array}$ & $\begin{array}{c}2 \text { BAIXA } \\
\text { "X".2; "Y".1; "Z".1 }\end{array}$ \\
\hline & $\begin{array}{l}\text { 1. População residente ou a trabalho em área de estabilidade } \\
\text { hidrogeomorfológica, passível a doenças por contato com água } \\
\text { contaminada e/ou vetores. }\end{array}$ & $\begin{array}{c}1 \text { BAIXA } \\
\text { A. } 1 ; \text { B. } 1 ; \text { C. } 1\end{array}$ \\
\hline
\end{tabular}

Fonte: Elaborado pelos autores, 2015.

Tendo em vista a leitura de como a vulnerabilidade se manifesta em diferentes contextos, de cada cidade, às margens do rio Capibaribe, faz-se uma ponderação dos grupos de fatores citados a fim de conduzir a proposição de organização esquemática de dados estatísticos que possam caracterizar os 
fatores de vulnerabilidade socioambiental nas cidades às margens do rio Capibaribe. A combinação das variantes de cada fator gera impreterivelmente níveis de vulnerabilidade diferenciada. Neste sentido, crê-se que cada realidade local deve ser vista como específica, indistintamente ao que vem sendo proposto nos programas e projetos do governo (ARAGÃO, 2017).

A Figura 3 expressa uma proposta de direcionamento às ações de mitigação à vulnerabilidade para áreas urbanas (ARAGÃO, 2017) que, embora não contemple indicadores numéricos, aponta fatores sociais, naturais e ambientais, em contraposição aos mecanismos de análise fechada, pautados em parâmetros estatísticos previamente estabelecidos e replicáveis a qualquer realidade.

A coluna "vulnerabilidade socioambiental" indica combinações possíveis entre os fatores sociais (A), Naturais (B) e Ambientais (C). Cada um destes fatores dispõe de três níveis de comprometimento, desde o nível "1", menos suscetível, ate o nível 3, mais suscetível. Desta feita, o nível de vulnerabilidade socioambiental de uma área será extremo se, em todos os fatores, a realidade identificada for a de nível 3 (A3, B3 e C3). Se todos os fatores apresentarem nível 2, haverá um nível médio de vulnerabilidade (A2, B2 e C2). Enquanto se todos os fatores estiverem caracterizados com níveis de suscetibilidade em nível 1,ter-se-á um nível de vulnerabilidade baixo.

Em síntese, a "vulnerabilidade socioambiental" de uma área e resultado da combinação dos níveis de comprometimento identificados em cada fator. As variações entre os níveis de vulnerabilidade extrema, media e baixa, estão representadas no quadro pelas letras "X", "Y" e "Z", pois indicam a possibilidade de situações intermediarias onde apenas um ou dois dos três fatores tenham, por exemplo, um nível 2. Nestes casos, chama-se atenção com as variáveis com o uso do sublinhado ("X".3, "Y".2, "Z".2).

A vulnerabilidade socioambiental é, nesta proposta, considerada alta 
quando determinada área, setor ou porção territorial da cidade apresentar ao menos um dos fatores (A, B ou C) em nível "3" e os demais fatores em nível "2" (tons vermelhos a laranja escuro no quadro). A vulnerabilidade socioambiental média será observada quando todos os fatores apresentarem nível "2" ou tiverem combinações de um fator em nível 3 e os outros em níveis "2" e "1" ou níveis "1" e "1" (tons em laranja claro no quadro). Já a vulnerabilidade baixa ocorrerá quando todos os fatores apresentarem nível 1 ou um fator nível 2 combinado a dois fatores com níveis 2 e 1 ou 1 e 1 (tons em azul no quadro).

As propostas que indicam um padrão de análise único desconsideram as variáveis que podem surgir de local para local, tornando-se possibilidades engessadas de prevenção, diagnose e/ou planejamento. A considerar a carência de dados estatísticos sobre as realidades socioambientais locais, bem como a importância de indicadores a proposta contida no quadro acima concede um caminho possível, no que tange aos níveis de comprometimento das margens fluviais.

Delimitar níveis de vulnerabilidade socioambiental em manchas urbanas, ao longo de um mesmo rio, demanda o planejamento integrado, tendo em vista a melhoria de vida das populações em situação de vulnerabilidade. Neste sentido, acredita-se que a ponderação numérica às características que compõem os níveis de comprometimento em cada fator deva ser concebida no âmbito da gestão intermunicipal do rio e das margens do rio.

O planejamento, a ocupação e o uso das margens de rios devem considerar, por isso, as peculiaridades de cada núcleo urbano e, principalmente, as interações resultantes da ocupação de jusante à montante de cada cidade. Em cada mancha urbana investigada foi possível detectar ocupações de alta vulnerabilidade, especificamente, a ocupação da Compesa em Santa Cruz do Capibaribe, a Rua da Barriguda em Limoeiro, e trechos de Nova Tiúma em São Lourenço da Mata (Figura 4). 
Figura 4. Localização de áreas de alta vulnerabilidade às margens do rio Capibaribe nas cidades investigadas.

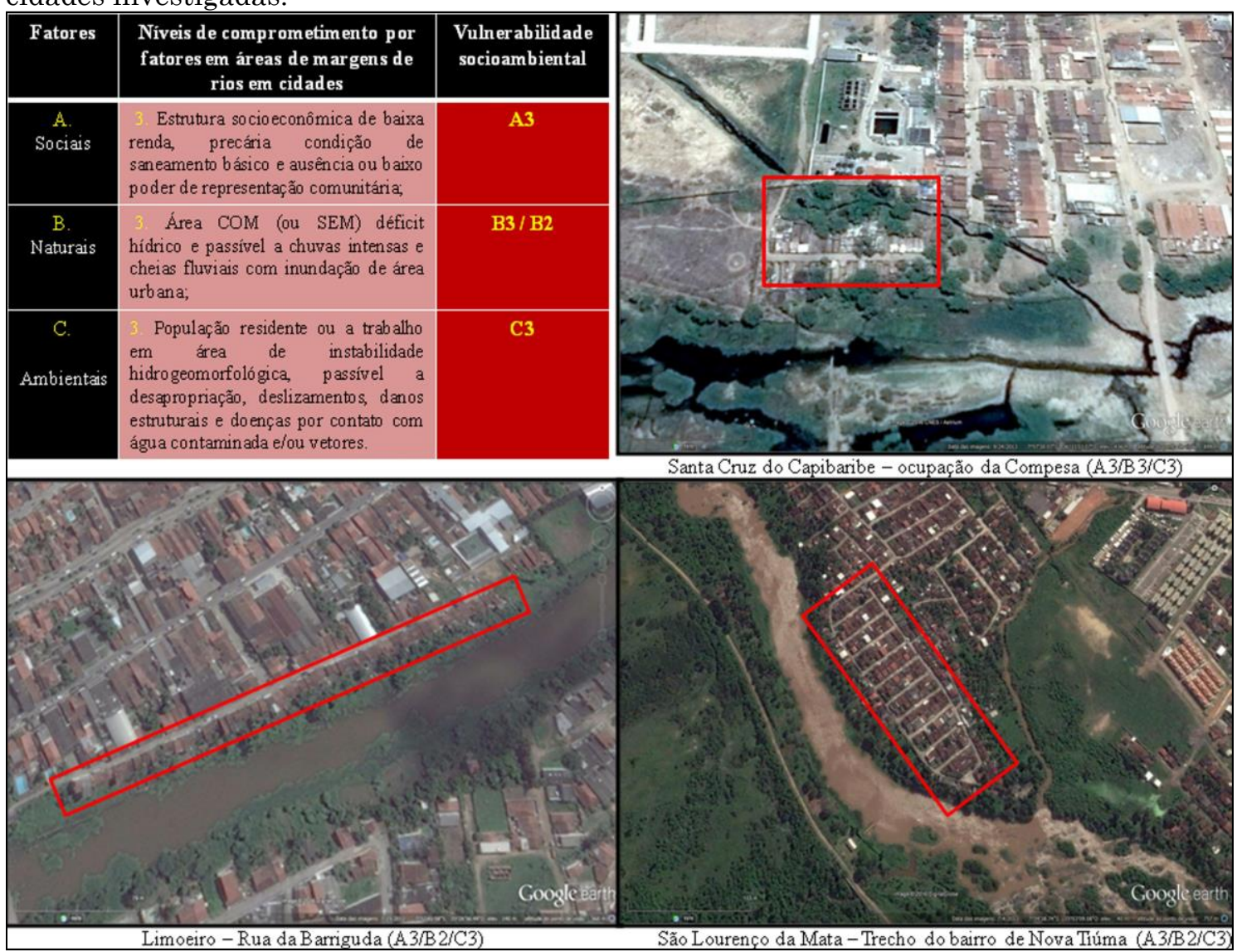

Fonte: Google Earth - adaptado, 2016.

Os desafios da gestão das margens de rios em manchas urbanas, bem como a diminuição da vulnerabilidade social nestas áreas, não findam na criação e/ou manutenção de obras de infraestrutura. Contudo, tendo em vista iniciativas referenciadas em países como Estados Unidos, Canadá (GORSKI, 2010), Alemanha (CUNHA, 2009) e, até mesmo no Brasil, sugerese a temática dos parques fluviais como linha de estudos e alternativa que poderia dar continuidade às reflexões e questionamentos aqui levantados.

Os resultados destas experiências têm indicado a reversibilidade dos problemas ambientais (como poluição dos rios e elevada vulnerabilidade), a recuperação da beleza estética dos ambientes das margens fluviais, a valorização das áreas adjacentes, incluindo as relações com o turismo, bem como o uso dos cursos fluviais e suas margens quando a produção dos 
parques é acompanhada de investimentos em saneamento básico, habitação, meio ambiente, entre outros setores.

A aplicação deste tipo de intervenção urbana requer, porém, o diagnóstico antecedente do espaço urbano a ser impactado com o parque. Demanda-se o levantamento dos diferentes tipos de ocupação e uso dos solos, os conflitos ligados a ocupação irregular, posse da terra, infraestrutura, além dos problemas socioambientais existentes. A negação destas condições alavanca o esfacelamento das propostas ou o agravamento dos conflitos, uma vez que as ações constituiriam, nesta hipótese, medidas estranhas e sem nexo com os conflitos existentes.

Ressalta-se ainda que em países como o Brasil, cuja formação histórica é marcada por processos de acumulação de riquezas, principalmente a terra, o tempo demandado a discussões e ações com fins à resolução de conflitos inclina-se a delonga, muito embora isto não sirva de negação, dada a indiscutível necessidade de melhoria da vida e diminuição das vulnerabilidades nas margens de rios em cidades brasileiras.

\section{Considerações Finais}

A relação das manchas urbanas no dinamismo da economia local e regional com as margens do rio Capibaribe tem efetivado um quadro contraditório dado pela degradação ambiental e vulnerabilidade de populações de baixa renda nas margens fluviais do Capibaribe paralelamente ao intenso dinamismo econômico das cidades analisadas. Destarte, ao longo das margens fluviais do Capibaribe, observa-se o acúmulo de danos socioambientais os quais, em cada tessitura urbana, são reconfigurados por fatores locais e extra locais.

Constatou-se nas manchas urbanas analisadas que suas margens fluviais possuem marcas de diversas formas urbanas e rurais. 
Conjuntamente aos resquícios da cobertura vegetal, foi possível enxergar a complexidade e a diversidade das relações universais entre sociedade e natureza, efetivadas ao longo da história.

$\mathrm{Na}$ prática, estas áreas têm sido semelhantemente concebidas segundo a lógica do espaço-mercadoria, onde o quadro de degradação de suas águas fluviais e os riscos de escassez consoante aos de enchentes, combinamse a exiguidade de espaços e (re)produção de áreas comprimidas entre as margens do rio e o centro dinâmico da economia local das cidades.

As diretrizes de conservação dos recursos naturais e de desenvolvimento socioeconômico dirigidas em esferas de gestão acima dos municípios, não têm sido eficientes para os problemas relativos às formas de ocupação, usos e vulnerabilidade socioambiental de populações de baixa renda em áreas de margens de rios. Para mitigar os problemas devem-se concretizar ações que atentem às variações locais de natureza das margens fluviais e dos dilemas sociais de ocupação e uso dos solos, bem como revisar as políticas existentes e o papel do Estado na gestão integrada das áreas de margens fluviais em manchas urbanas.

Desta feita, revisou-se a hipótese inicial, concebendo que, além da dificuldade de intervenções eficientes por parte do Estado, a existência de distintas intencionalidades dos agentes sociais nas cidades expressam a multiplicidade dos interesses e das formas de ocupação e uso urbano dos solos. Isto também resulta no tardeamento dos preceitos coletivos de conservação ambiental e justiça social, o que têm impactado na reprodutibilidade das condições de vulnerabilidade socioambiental dos grupos sociais de menor poder aquisitivo.

Este quadro, amiúde, aponta a um processo de degradação ambiental e segregação socioespacial que majora a precária inclusão social das populações pobres nas cidades e externa, entre todos os níveis, a desarticulação da gestão pública dos rios e suas margens. Este processo contribui ao longo do tempo para o crescimento desordenado das cidades 
que, sem a devida atenção ao processo de ocupação e uso dos solos, contribui para as dinâmicas de degradação das margens fluviais, atualmente, espaços utilizados a mercê de suas fragilidades e potencialidades.

Ademais, entende-se que quaisquer alteração nos sistemas naturais das margens ou sobre as sociedades que vivem nestes ambientes impacta na reorganização lógica dos elementos constituintes do espaço. Este fato resulta na reconfiguração das trocas de matéria e energia nos sistemas, quer sejam naturais ou sociais.

Haja vista a mitigação da vulnerabilidade socioambiental existente nas margens do rio Capibaribe, a partir de fatores sociais, naturais e ambientais propostos, e o papel relevante dos agentes públicos neste processo, acredita-se ser necessário avançar na construção de indicadores de vulnerabilidade, estabelecendo parâmetros quantitativos, algo deveras não explorado neste estudo, mas tão somente fomentado.

Por fim, destaca-se a possibilidade de reflexão de outras realidades complexas, no contexto da América Latina, haja vista a existência dos fatores observados neste estudo, não ser restrita aos casos aqui analisados. Quadros semelhantes, especialmente no Brasil, interpõem-se sem estudos semelhantes e podem, se efetivados, contribuir para corroborar as constatações indicadas, revisá-las e/ou negá-las, evidentemente tratando-se de temática inconclusa e necessária.

\section{Agradecimentos}

Agradecimentos à Coordenação de Aperfeiçoamento de Pessoal de Nível Superior (CAPES) pelo fomento financeiro e ao Programa de Pós Graduação em Desenvolvimento e Meio Ambiente da Universidade Federal de Pernambuco (PRODEMA/UFPE). 


\section{Referências}

AB'SABER, A. N. Bases conceptuais e papel do conhecimento na previsão de impactos. In: MUller-PlantenBerG, C.; AB'SABER, A. N. (Orgs.). Previsão de Impactos: o estudo de impacto ambiental no leste, oeste e sul. São Paulo: Edusp, 1994. p. 27 - 49.

. Um conceito de Geomorfologia a Serviço das Pesquisas Sobre o Quaternário.

Geomorfologia. GEOG/USP. São Paulo, n. 18, p. 1-23, 1969.

ALEDO, A.; SULAIMAN, S. La incuestionabilidad Del riesgo. Ambiente \& Sociedade. São Paulo v. 17, n. 4, p. 9-16, out.-dez., 2014. https://doi.org/10.1590/18094422ASOCEx01V1742014

APAC - Agência Pernambucana de Águas e Climas. Bacias hidrográficas: rio Capibaribe. Disponível em: <http:/z/www.apac.pe.gov.br/pagina.php?page_id=5\&subpage_id=14>. Acesso em: 12 de maio de 2012.

ARAGÃO, J. P. G. de V.; GOMES, E. T. A. Margens do rio Capibaribe na (re)produção do urbano em cidades pequenas: vulnerabilidades e formas de ocupação e uso. In: ENCONTRO NACIONAL DE GEÓGRAFOS. 2016. São Luís. Anais[...]. São Luís: UFMA, 2016. p. 1 - 12. - Paradoxos do uso dos solos nas margens do rio Capibaribe: vulnerabilidades socioambientais em áreas urbanas. Revista Brasileira de Agrotecnologia. v. 7, n. 3, p. $148-166,2017$.

ARAGÃO, J. P. G. de V. Uso e ocupação das margens do rio Capibaribe: vulnerabilidades socioambientais $\mathrm{m}$ áreas urbanas. 2017. $294 \mathrm{f}$. Tese (Doutorado em Desenvolvimento e Meio Ambiente) - Recife: Universidade Federal de Pernambuco, 2017.

BANCO CENTRAL DO BRASIL. Número de agências bancárias entre 2010 e 2014. Disponível em: <http://www.bde.pe.gov.br/estruturacaogeral/conteudo_site2.aspx>. Acesso em: 15 de janeiro de 2016.

BERTRAND, G. Paysage ET Geographie Phisique Globale: equisse méthodologique. Rev. Géogr. Des Pyrenées ET Du Sud-ouest (Toulouse), v.39, n.3, p. 249-272, 1968. https://doi.org/10.3406/rgpso.1968.4553

BRASIL. Ministério das Cidades / Instituto de Pesquisas Tecnológicas. Mapeamento de riscos em encostas e margens de rios. Brasília: Instituto de Pesquisas Tecnológicas IPT, 2007.

Lei $N^{\circ}$ 12.651, de 25 de maio de 2012. Dispõe sobre a proteção da vegetação nativa; altera as Leis $\mathrm{n}^{\circ}$ 6.938, de 31 de agosto de 1981, 9.393, de 19 de dezembro de 1996, e 11.428, de 22 de dezembro de 2006; revoga as Leis $\mathrm{n}^{\circ} 4.771$, de 15 de setembro de 1965, e 7.754, de 14 de abril de 1989, e a Medida Provisória n ${ }^{\circ}$ 2.166-67, de 24 de agosto de 2001; e dá outras providências. Disponível em: <http://www.planalto.gov.br/ccivil 03/ ato20112014/2012/lei/l12651.htm>. Acesso em: 12 de março de 2016.

CELPE - Companhia Energética de Pernambuco. Consumo e consumidores de energia elétrica entre 1985 e $2015 . \quad$ Disponível em: <http://www.bde.pe.gov.br/estruturacaogeral/conteudo_site2.aspx $\geq$. Acesso em: 15 de janeiro de 2016.

COMPESA - Companhia Pernambucana de Saneamento. Bacia Hidrográfica do rio Capibaribe. Recife: Monitoramento dos reservatórios, 2009.

CUNHA, S. B. Canais fluviais e a questão ambiental. In: CUNHA, Sandra Baptista; GUERRA A. J. T. A questão ambiental: diferentes abordagens. Rio de Janeiro: Bertrand Brasil, 2009. p. $219-237$.

DETRAN - Departamento Estadual de Trânsito de Pernambuco. Frota de veículos, por tipo. Disponível em: <http://www.bde.pe.gov.br/estruturacaogeral/conteudo site2.aspx>. Acesso em: 15 de janeiro de 2016.

GORSKI, M. C. B. Rios e cidades: ruptura e reconciliação. São Paulo: Edidota Senac São Paulo, 2010.

GUERRA, A. T.; GUERRA, A. J. T. Novo Dicionário Geológico Geomorfológico. Rio de Janeiro: Bertrand Brasil, 2006. 
HEWITT, K. The Idea of calamity in a technocratic age. Boston: Allen and unwin, 1983.

IBGE - Instituto Brasileiro de Geografia e Estatística. Sinopse dos censos demográficos 2000 e 2010: domicílios particulares ocupados, localizados por área. Disponível em: <http://www.bde.pe.gov.br/estruturacaogeral/conteudo_site2.aspx $>$. Acesso em: 15 de janeiro de 2016.

Pesquisa de Informações Básicas Municipais. Disponível em: $<$ http://www.ibge.gov.br/home/estatistica/economia/perfilmunic/ $>$. Acesso em: 02 de abril de 2015.

MENDONÇA, F. de A. Riscos, vulnerabilidade e abordagem socioambiental urbana: uma reflexão a partir da RMC e de Curitiba. Revista Desenvolvimento e Meio Ambiente. Editora UFPR. n. 10, p. 139-148, jul./dez., 2004. https://doi.org/10.5380/dma.v10i0.3102 MINISTÉRIO DO TRABALHO E EMPREGO. Estabelecimentos por setor de atividades entre 1998 e 2015.2 Disponível em: $<$ http://www.bde.pe.gov.br/estruturacaogeral/conteudo_site2.aspx $>$. Acesso em: 15 de janeiro de 2016.

MONTEIRO, C. A. de F. Geossistemas a história de uma procura. São Paulo: Contexto, 2001.

MORA, L. D. L.; XAVIER, M. G. P.; SARABIA, M. L. A cidade de Santa Cruz do Capibaribe e seu dinâmico desenvolvimento local: em foco as mudanças. In: 5ÈME COLLOQUE DE I'IFBAE. 2009. Grenoble. Anais[...]. Grenoble: IFBAE. 2009. p. 1 - 17.

PORTO, M. F. de S. Uma Ecologia Política dos Riscos: princípios para integramos o local e o global na promoção da saúde e da justiça ambiental. Rio de Janeiro: Fiocruz, 2007. https://doi.org/10.7476/9788575413777

POPPER, K. R. A lógica da pesquisa científica. São Paulo: Cultrix, 2013.

PREFEITURA MUNICIPAL DE SÃO LOURENÇO DA MATA. Lei Orgânica Municipal. São Lourenço da Mata: Sala da Seções, 2008.

PNUD - Programa das Nações Unidas para o Desenvolvimento. Sostener El progresso humano: reducir vulnerabilidades e construir resiliencia. Nova York: ONU/PNUD, 2014.

QUARANTELLI, E. L. What is disaster? London: Routledge, 1998.

ROSS, J. L. S. Análises e Sínteses na Abordagem Geográfica da Pesquisa para o Planejamento Ambiental. Revista do Departamento de Geografia da USP. São Paulo. n.9, p.65-75, 1995. https://doi.org/10.7154/RDG.1995.0009.0006

SANTOS, M. Espaço e método. São Paulo: Editora da Universidade de São Paulo, 2012.

A natureza do espaço. Edusp: São Paulo, 2006.

SANTOS, J. de O. Relações entre fragilidade ambiental e vulnerabilidade social na susceptibilidade aos riscos. Mercator, Fortaleza, v. 14, n. 2, p. 75-90, mai./ago., 2015. https://doi.org/10.4215/RM2015.1402.0005

SRHE/PE - Secretaria de Recursos Hídricos e Energéticos do Estado de Pernambuco. Plano Hidroambiental da Bacia Hidrográfica do Rio Capibaribe. Recife: Governo do Estado de Pernambuco, 2010.

SOTCHAVA, V. B. Por uma teoria de classificação de geossistemas da vida terrestre. São Paulo: IGEOG-USP, 1978.

THOURET, J. Os riscos nos países em desenvolvimento. In: VEYRET, Yvette (Org.) Os riscos: o homem como agressor e vítima do meio ambiente. São Paulo: Contexto, 2007. p. 83 -85 .

TRICART, J. Ecogeography and rural management: a contribuiton to the international geosphere-biosphere Programme. Paris: Longmam Scientific \& Technical, 1992.

Ecodinâmica. Rio de Janeiro: IBGE, 1977.

VILAÇA, A. À sombra de dois pinheiros. Rio de Janeiro: Arquimedes, 1973.

WISNER, B; BLAIKIE, P.; CANNON, T. e DAVIS, I. At risk: natural hazards, people's vulnerability and disasters. London: Routledge, 2004. 